All letters are subject to editing and may be shortened. General letters can be sent to bjgpdisciarcgp.org.uk (please include your postal address for publication), and letters responding directly to BJGParticles can be submitted online via eLetters. We regret we cannot notify authors regarding publication.

For submission instructions visit: bjgp.org/letters

\section{Inequalities in CKD management can be overcome}

Molokhia et al' report on chronic kidney disease (CKD) coding in primary care records in a multi-ethnic area of South London, demonstrating lower rates in all ethnic minority groups compared with the white population, which contributes to health inequalities. They also confirm the findings based on the National Chronic Kidney Disease audit2,3 that absence of CKD coding is associated with worse outcomes for blood pressure management and statin prescribing, and is associated with a greater burden of non-steroidal anti-inflammatory drug (NSAID) prescribing.

However, their study was based on a primary care dataset from 2013. Is it possible that Lambeth practices have improved coding rates since then? In East London there were similar low rates of CKD coding prior to 2015, when a quality improvement project promoting coding for CKD as part of a community renal service was introduced.

We combined feedback to practices, using quarterly dashboards to show performance relative to others, and engaged with the clinical commissioning groups (CCGs) to include CKD coding in Local Enhanced Services contracts. Over a 2-year period we showed a sustained rise in CKD coding to $>85 \%$ across all the CCGs involved in the programme. $^{4}$

Table 1 shows the dashboard for Newham
CCG (with 7822 CKD cases) from July 2020. It illustrates the high rates of coding across all age bands and all ethnic groups, with the highest recording rates in black African and black Caribbean. Results are similar across all participating CCGs.

This demonstrates the effectiveness of quality improvement programmes, which can improve the reach of effective interventions and decrease the corrosive effects of health inequalities.

There are further improvements to be made in East London - particularly in the offer of statins to younger people with CKD and improving BP control in those with both diabetes and CKD.

Using the opportunities to work across sectors and incentivise primary care in this way can reduce the impact of cardiovascular and end-stage kidney disease for those ethnic minorities at greatest risk.

\section{Sally Hull,}

Reader in Primary Care, Queen Mary

University of London, London.

Email: s.a.hulldamul.ac.uk

Neil Ashman,

Consultant Nephrologist, Barts Health NHS Trust, London.

Gavin Dreyer,

Consultant Nephrologist, Barts Health NHS Trust, London.

\section{REFERENCES}

1. Molokhia M, Okoli GN, Redmond P, et al. Uncoded chronic kidney disease in primary care: a crosssectional study of inequalities and cardiovascular

Table 1. Newham CCG dashboard, July 2020

\begin{tabular}{|c|c|c|c|c|c|c|}
\hline & & $\begin{array}{c}\text { CKD cases, } \\
n\end{array}$ & $\begin{array}{c}\text { Diabetes } \\
\text { comorbidity, } \\
\%\end{array}$ & $\begin{array}{c}\text { Hypertension } \\
\text { comorbidity, } \\
\%\end{array}$ & $\begin{array}{c}\text { CKD, coded, } \\
\%\end{array}$ & $\begin{array}{l}\text { Prescribed } \\
\text { statin, \% }\end{array}$ \\
\hline \multirow{4}{*}{$\begin{array}{l}\text { Age band, }{ }^{a} \\
\text { years }\end{array}$} & 18-39 & 94 & 13.8 & 44.7 & 79.8 & 20.2 \\
\hline & 40-59 & 1268 & 32.9 & 59.8 & 80.2 & 52.8 \\
\hline & $60-79$ & 3847 & 48.3 & 75.7 & 86.4 & 77.3 \\
\hline & $\geq 80$ & 2257 & 45.5 & 85.4 & 91.3 & 74.7 \\
\hline \multirow{5}{*}{ Ethnic group } & White & 2971 & 29.1 & 70.0 & 85.0 & 66.9 \\
\hline & South Asian & 3251 & 56.5 & 76.7 & 87.8 & 78.8 \\
\hline & Black & 1163 & 49.3 & 87.7 & 90.5 & 65.6 \\
\hline & Other & 327 & 48.6 & 74.9 & 83.2 & 74.3 \\
\hline & Not recorded & 109 & 26.6 & 67.9 & 72.5 & 56.0 \\
\hline
\end{tabular}

Data missing. $C C G=$ clinical commissioning group. $C K D=$ chronic kidney disease

disease risk management. Br J Gen Pract 2020; DOI: https://doi.org/10.3399/bjgp20X713105.

2. Nitsch D, Caplin B, Hull SA, et al. National Chronic Kidney Disease Audit: national report (Part 1). London: Healthcare Quality Improvement Partnership, 2017. mww.lshtm.ac.uk/files/ckd_audit report.pdf (accessed 8 Dec 2020).

3. Kim LG, Cleary F, Wheeler DC, et al. How do primary care doctors in England and Wales code and manage people with chronic kidney disease? Results from the National Chronic Kidney Disease Audit. Nephrol Dial Transplant 2018; 33(8): 1373-1379.

4. Hull SA, Rajabzadeh V, Thomas N, et al. Improving coding and primary care management for patients with chronic kidney disease: an observational controlled study in East London. Br J Gen Pract 2019. DOl: https://doi.org/10.3399/bjgp19X704105.

DOI: https://doi.org/10.3399/bjgp21X71438

\section{It's time to look again at GP funding}

The COVID pandemic has shone a spotlight on long recognised inequalities in health outcomes, ${ }^{1}$ which have been widening in recent years. ${ }^{2}$ Castle et al ${ }^{3}$ describe how the general practice funding formula negatively impacts the ability of general practice teams to provide equitable care, with the risk of further widening these inequalities.

The Health Foundation's recent report Level or Not? ${ }^{4}$ outlines the increased workload for practices serving our most deprived areas. It finds that, once adjustments are made for the associated increased workload in poorer areas, these practices receive 7\% less funding per patient than those serving less deprived populations. Unsurprisingly, the report Who Gets In? finds that those living in the most deprived areas are less likely to report a positive experience of general practice care. $^{5}$

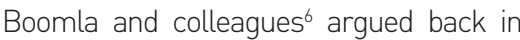
2014 for a fairer distribution of funding to reflect the additional workload in deprived areas. Their data on consultation rates for those in the most and least deprived quintiles of multiple deprivation found vastly increased consultation rates in deprived areas. This reflected Marmot's finding of an 18-year-gap difference in disability-free life expectancy, ${ }^{7}$ and highlighted the need to recognise the very tangible additional workload this brings to general practice teams.

The partnership model, which underpins 